Artigos

Volume 10 - 2020|n. 10

\title{
Valorização dos funcionários de escola: as condições de remuneração dos profissionais em dez municípios da Região Metropolitana de Curitiba/PR ${ }^{1}$
}

\author{
Mariana Moschkovich Athayde \\ Universidade Federal do Paraná (UFPR), Curitiba/PR - Brasil
}

\section{Resumo}

Os funcionários de escola, embora atuantes nos estabelecimentos de ensino desde a instituição da educação formal no Brasil, seguem subvalorizados em detrimento dos profissionais do magistério. Este artigo busca dar luz à sua situação, mais especificamente no âmbito da remuneração, a partir da proposição de indicadores com base na fonte de dados de Remuneração dos Profissionais da Educação (custeados pelo Fundeb) disponível no sistema SIOPE. Propõe-se três grupos de indicadores para análise da remuneração desses profissionais: (1) indicador de vencimento básico médio dos funcionários da educação; (2) indicadores de vencimento básico médio por categoria profissional; e (3) indicadores de vencimento básico média dos funcionários por local de exercício. Identificaram-se problemas de integridade nos dados da Região Metropolitana de Curitiba/PR disponíveis no sistema SIOPE, o que acarretou em restrições na sua utilização. Contudo, identificou-se que estes profissionais ganharam, no ano de 2017, em média, 1,6 salários mínimos para uma jornada de 40h semanais.

Palavras-chave: Funcionários de escola. Remuneração. Valorização dos profissionais da educação. Indicadores Educacionais. SIOPE.

\section{Valuing school staff: the remuneration conditions of professionals in ten cities from Metropolitan Region of Curitiba / PR}

\section{Abstract}

School employees, although working in educational establishments since the institution of formal education in Brazil, remain undervalued to the detriment of teaching professionals. This article seeks to shed light on this situation, more specifically in the scope of remuneration, based on the proposition of indicators based on the data source of Compensation for Education Professionals (funded by Fundeb) available in the SIOPE system. Three groups of indicators are proposed for analyzing the remuneration of these professionals: (1) average basic salary indicator for education employees; (2) average basic salary indicators by professional category; and (3) average basic salary indicators for employees by location. Problems of integrity were identified in the data from the Metropolitan Region of Curitiba / PR available in the SIOPE system, which resulted in restrictions on its use. However, it was identified that these professionals earned, in 2017, on average, 1.6 minimum wages for a 40-hour week.

Keywords: School staff. Salary. Valuing education professionals. Educational Indicators. SIOPE.

\footnotetext{
1 O presente trabalho foi realizado com apoio da Coordenação de Aperfeiçoamento de Pessoal de Nível Superior - Brasil (CAPES).
} 
Valorização dos funcionários de escola

\section{Introdução}

O debate sobre a qualidade da educação pública no Brasil também abrange o seu financiamento e a valorização de seus profissionais. Esses temas se conectam explicitamente quando tratamos da remuneração dos profissionais da educação. Historicamente invisibilizados (MONLEVADE, 2014), os funcionários de escola passam a fazer parte legalmente dessa categoria com a promulgação da Emenda Constitucional $n^{\circ} 53 / 2006$, que altera no texto constitucional a nomenclatura "profissionais do magistério" para "profissionais da educação escolar" e incide, por meio da Lei no 12.014/2009, na Lei no 9.394/1996 - LDB, reconhecendo os funcionários como profissionais da educação escolar básica. No entanto, permanecem subvalorizados em relação aos profissionais do magistério (ASSIS, 2017).

Um exemplo dessa situação é o levantamento do perfil de docentes a partir do Censo Escolar, o que não acontece para funcionários de escola, apesar de essa ser uma estratégia detalhada no Plano Nacional de Educação - PNE 2014/2024 para o cumprimento da Meta 18. Ainda, temos o estabelecimento do Piso Salarial Nacional para Profissionais do Magistério Público da Educação Básica instituído desde 2008, e que, apesar de haver Diretrizes Nacionais para os Planos de Carreira e Remuneração dos Funcionários da Educação Básica Pública desde 2010, ainda não há legislação que determine o seu piso.

Com o objetivo de trazer luz ao tema da remuneração dessa categoria, este artigo propõe uma pesquisa exploratória a partir da base de dados do formulário "Remuneração dos Profissionais da Educação - Fundeb", declarada pelos municípios e coletada pelo Sistema de Informações sobre Orçamentos Públicos em Educação (SIOPE) em 2017 (FNDE, 2017b), tendo como questão central a proposição de indicadores que descrevam a remuneração média recebida pelos funcionários de escola.

\section{Entendendo a valorização a partir da remuneração}

É importante ressaltar que pouco se encontra na literatura acadêmica sobre a valorização específica dos funcionários de escola (ASSIS, 2015). Entretanto, apesar de a valorização de trabalhadores da educação ainda ser um conceito em disputa (GROCHOSKA, 2015), muito se escreve sobre a valorização de profissionais do magistério. Entendendo ambas as categorias como profissionais da educação escolar, optou-se neste artigo por estender aos funcionários a aplicação do conceito apresentado por Grochoska (2015), que compreende a valorização docente como valorização do trabalhador da educação em um Estado Democrático de Direito.

A valorização, ligada à qualidade de vida do trabalhador, tem como mecanismo a carreira, viabilizada pela formação, condições de trabalho e remuneração. Assim, compreende-se que a condição de o professor ser entendido como "[...] um profissional, mas também um ser humano com vontades e necessidades básicas e que por meio da sua profissão precisa produzir sua vida e de preferência com qualidade" (GROCHOSKA, 2015, p. 93) é mútua ao funcionário de escola.

\section{Políticas que incidem na remuneração de profissionais da educação}

Podem ser considerados marcos legislativos da temática da remuneração: a) a Emenda Constitucional $n^{\circ}$ 53/2006, que cria o Fundo de Manutenção e Desenvolvimento da Educação 
Básica e de Valorização dos Profissionais da Educação (Fundeb) e institui o piso salarial profissional nacional para os profissionais da educação escolar pública (BRASIL, 2006); b) a Lei $n^{\circ} 11.738$, de 16 de julho de 2008, que regulamenta o piso salarial para profissionais do magistério (PSPN) (BRASIL, 2008a); c) a Resolução CNE/CEB $n^{\circ} 2 / 2009$, que fixa as Diretrizes Nacionais para os Planos de Carreira e Remuneração dos Profissionais do Magistério da Educação Básica Pública (BRASIL, 2009b); d) a Resolução CNE/CEB $n^{\circ}$ 5/2010, Fixa as Diretrizes Nacionais para os Planos de Carreira e Remuneração dos Funcionários da Educação Básica Pública (BRASIL, 2010); e e) a Lei $n^{\circ} 13.005$, de 25 de junho de 2014, que aprova o Plano Nacional de Educação (PNE), que em sua Meta 17 especifica a valorização a partir da remuneração dos profissionais do magistério (BRASIL, 2014).

Neste artigo, trabalha-se com a base de dados que informa a remuneração paga especificamente com recursos provenientes do Fundeb, caracterizado como um fundo contábil que redistribui as verbas vinculadas à educação de acordo com o número de estudantes matriculados, e é formado por $20 \%$ da arrecadação de diversos impostos ${ }^{2}$ de estados e municípios e a complementação da União (BRASIL, 2007). Este substituiu o Fundo de Manutenção e Desenvolvimento do Ensino Fundamental e de Valorização do Magistério (Fundef), criado a partir da Emenda Constitucional $n^{\circ}$ 14/1996 (BRASIL, 1996a), que tinha como foco o ensino fundamental e a valorização do magistério (EDNIR; BASSI, 2009). Ainda que o Fundeb trate de profissionais da educação no geral, e inclua a obrigação de entes Estados, Distritos Federais e Municípios em implantar Planos de Carreira e remuneração para todos, indica especificidades relacionadas à atuação do magistério. Há, por exemplo, a determinação do piso nacional para a categoria docente e a determinação de que, do recebido pelos estados e municípios a partir do fundo, após redistribuição proporcional às matriculas dos entes, no mínimo 60\% deva ser aplicado na remuneração de profissionais do magistério.

Gouveia e Bassi (2016) indicam que o estabelecimento de tais políticas fez com que grande parte dos recursos provenientes da vinculação de impostos passasse a ser movimentado pelos fundos. Os autores realizaram análise do vencimento dos professores nos estados do Paraná e de Santa Catarina e apontaram que, mesmo com as políticas de fundos, somente com a vigência do PSPN houve crescimento nos vencimentos. $E$ que, no entanto, é possível observar um achatamento da carreira docente, uma vez que a elevação do vencimento de final de carreira não acompanha a elevação do vencimento inicial.

Para funcionários de escola, ainda que tenhamos legislação que fixe diretrizes para planos de carreira e remuneração, não há legislação referente a um piso nacional para a categoria, conforme apontado anteriormente. Nesse sentido, este artigo analisa a

2 A Lei $n^{\circ} 11.494$, de 20 de junho de 2007 (BRASIL, 2007) especifica os impostos: I - sobre transmissão causa mortis e doação de quaisquer bens ou direitos; II - sobre operações relativas à circulação de mercadorias e sobre prestações de serviços de transportes interestadual e intermunicipal e de comunicação; III - sobre a propriedade de veículos automotores; IV - parcela do produto da arrecadação do imposto que a União eventualmente instituir; $\mathrm{V}$ - parcela do produto da arrecadação do imposto sobre a propriedade territorial rural, relativamente a imóveis situados nos Municípios; VI - parcela do produto da arrecadação do imposto sobre renda e proventos de qualquer natureza e do imposto sobre produtos industrializados devida ao Fundo de Participação dos Estados e do Distrito Federal - FPE; VII - parcela do produto da arrecadação do imposto sobre renda e proventos de qualquer natureza e do imposto sobre produtos industrializados devida ao Fundo de Participação dos Municípios - FPM; VIII - parcela do produto da arrecadação do imposto sobre produtos industrializados devida aos Estados e ao Distrito Federal; IX - receitas da dívida ativa tributária relativa aos impostos previstos neste artigo, bem como juros e multas eventualmente incidentes. 
Valorização dos funcionários de escola

remuneração média a partir do vencimento básico declarado no SIOPE, a fim de analisar o salário inicial que se efetivou nos municípios para esses profissionais.

Os funcionários de escola estão presentes desde a instituição de estabelecimentos escolares no Brasil. No entanto, por não estarem diretamente ligados ao processo de ensino aprendizagem, atuando fora da sala de aula, são historicamente invisibilizados (MONLEVADE, 2014). O processo de visibilização dos funcionários inicia-se com o autorreconhecimento da categoria culminando em formação de sindicatos e associações na década de 1980 e na unificação da luta com a dos profissionais docentes na Confederação Nacional dos Trabalhadores em Educação (CNTE) em 1990 (MONLEVADE, 2014).

O percurso de reconhecimento dos funcionários de escola, como trabalhadores da educação nas políticas educacionais, inicia-se em 2005 com o Parecer CNE/CEB 16/2005 (BRASIL, 2005b) e a Resolução CNE/CEB n 5/2005, que propõe e inclui nas Diretrizes Curriculares Nacionais a área de "Serviços de Apoio Escolar" como $21^{\text {a }}$ Área Profissional

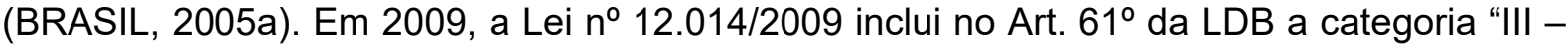
trabalhadores em educação, portadores de diploma de curso técnico ou superior em área pedagógica ou afim" (BRASIL, 2009a). A partir de então, segue-se a promulgação de leis, decretos e resoluções que visam tratar da formação, carreira e remuneração de tais trabalhadores, mas que nem sempre foram efetivadas (ASSIS, 2015).

Entende-se como funcionários de escola os profissionais que atuam nas funções secretaria escolar, alimentação escolar, multimeios didáticos e infraestrutura, conforme Parecer CNE/CEB 16/2005 já mencionado (BRASIL, 2005b). É importante destacar que não é possível realizar um levantamento censitário do quantitativo ou da formação dos profissionais atuantes, uma vez que não são contemplados pelo Censo Escolar e não existe censo específico da categoria. Ainda, a base de dados utilizada neste estudo os categoriza a partir da função realizada e possibilita verificação do local de lotação, o que permite a aplicação parcial desta proposta, conforme detalhamento metodológico a seguir.

\section{Aspectos Metodológicos}

No presente trabalho, realizou-se um estudo observacional, que verifica e mede características específicas, sem realizar manipulação dos elementos (TRIOLA, 1998), para a proposição de indicadores de remuneração dos profissionais da educação, mais especificamente dos funcionários de escola. A fonte de dados quantitativos utilizada foi o Sistema de Informações sobre Orçamentos Públicos em Educação (SIOPE) (FNDE, 2017b). Essa ferramenta foi instituída pelo Ministério da Educação (MEC), através da Portaria/MEC $n^{\circ} 6 / 2006$, para realizar a coleta, processamento e divulgação dos dados referentes a receitas e despesas municipais, estaduais, distritais e da União no que compete à educação.

Desde 2017 o SIOPE solicita aos entes federados a inclusão dos dados da remuneração de profissionais da educação realizada com recursos oriundos do Fundeb. Por não ter sido possível, durante o período de escrita deste estudo, identificar literatura que trate das restrições da fonte de dados, e considerando-se o curto histórico de coleta dos dados do sistema, optou-se por trabalhar com um número restrito de localidades em nível municipal, a fim de permitir uma análise mais aprofundada das limitações dos dados disponíveis, detalhadas a seguir. 
Valorização dos funcionários de escola

\section{Sobre a base de dados}

O portal eletrônico do SIOPE (FNDE, 2017b) disponibiliza os dados de remuneração de profissionais da educação a partir de consulta do município ou em lote (por estado), com as variáveis apresentadas no Quadro 1 abaixo.

Quadro 1 - Variáveis do banco de dados do SIOPE 'Remuneração dos Profissionais da Educação', 2017

\begin{tabular}{|l|l|}
\hline \multicolumn{1}{|c|}{ Código da Variável } & \\
\hline AN_EXERCICIO & Ano de referência do pagamento \\
\hline NU_PERIODO & Bimestre de referência do pagamento \\
\hline ME_EXERCICIO & Mês de referência do pagamento \\
\hline CO_UF & Código do Estado \\
\hline NO_UF & Nome do Estado \\
\hline CO_MUNICIPIO & Código do Município \\
\hline NO_MUNICIPIO & Nome do Município \\
\hline NU_REMUNERACAO & Número da Remuneração \\
\hline NO_PROFISSIONAL & Nome do profissional da educação \\
\hline LOCAL_EXERCICIO & Nome do local de exercício \\
\hline CARGA_HORARIA & Carga horaria (semanal) \\
\hline TP_CATEGORIA & Tipo de categoria* \\
\hline CATEG_PROFISSIONAL & Categoria profissional ${ }^{*}$ \\
\hline VL_SALARIO & Vencimento básico \\
\hline VL_PARC_MINIMA_FUNDEB & Remuneração bruta com a parcela mínima de 60\% do FUNDEB \\
\hline VL_PARC_MAXIMA_FUNDEB & Remuneração bruta com a parcela máxima de 40\% do FUNDEB \\
\hline VL_OUTRAS_RECEITAS & Remuneração bruta com outras receitas \\
\hline VL_TOTAL & Total da remuneração \\
\hline
\end{tabular}

*De acordo com Resolução CNE/CEB n 1/2008.

Fonte: Adaptado do Manual do Siope (FNDE, 2017a).

O sistema trabalha com dois tipos de categorias de profissionais na variável 'Tipo de categoria': 'Profissionais do magistério', descrita a partir da Resolução MEC/CNE no 1/2008 (BRASIL, 2008b), e 'Outros profissionais da educação'. Estes últimos serão considerados neste artigo como funcionários, e estão descritos na variável 'Categoria profissional' como 'Auxiliar/Assistente Educacional', 'Profissionais que exercem funções de secretaria escolar, alimentação escolar (merendeiras), multimeios didáticos e infraestrutura' e 'Profissionais que atuam na realização das atividades requeridos nos ambientes de secretaria, de manutenção em geral'. A análise da base de dados mostra que existem registros cujo local de exercício é a Secretaria Municipal de Educação ou órgãos afins. Por isso, não foi possível trabalhar com o conceito proposto inicialmente de funcionários de escola, tendo sido utilizado o termo funcionários da educação ou simplesmente funcionários para indicar os profissionais que não atuam no magistério. Os indicadores propostos neste artigo incluem a análise destas variáveis. Ainda sobre essa categorização, observa-se que na descrição dos profissionais do magistério constam trabalhadores com atuação em sala de aula ou funções consideradas de apoio direto, como direção, coordenação pedagógica e etc. 
Os dados de remuneração utilizados neste artigo se referem especificamente à base que apresenta as informações em lote dos municípios, ou seja, das escolas municipais do estado do Paraná. Conforme a Tabela 1, apresentada a seguir, observou-se que, do total de 399 municípios do estado, 385 ou 96,5\% realizaram a declaração da remuneração dos profissionais da educação no sistema. Destes, 95,1\% incluíram informações no sistema para todos os meses de 2017 e $75,2 \%$ incluíram informações sobre "Outros profissionais da educação". No entanto, somente $45,1 \%$ dos municípios abrangeram ambos os fatores, ou seja, declararam profissionais não docentes em todos os meses de 2017.

Tabela 1 - Descrição do banco de dados da Remuneração dos Profissionais da Educação, Paraná, 2017

\begin{tabular}{|l|c|c|}
\hline Municípios que declararam remuneração & 385 & $100 \%$ \\
\hline Declararam em todos os meses & 366 & $95,1 \%$ \\
\hline Declararam “Outros Profissionais da educação” & 300 & $77,9 \%$ \\
\hline Ambos & 180 & $46,8 \%$ \\
\hline
\end{tabular}

Fonte: Elaborado pela autora a partir do SIOPE (FNDE, 2017b).

\section{Construindo os indicadores de remuneração média}

Como mencionado anteriormente, por abranger uma análise de uma base de dados com apenas um ano de histórico de imputação de dados, optou-se por selecionar um número menor de municípios, a fim de compreender com maior especificidade as informações disponibilizadas e facilitar a compreensão de suas limitações ao estudo. Contudo, para a elaboração dos indicadores de vencimento médio, foi necessário garantir algumas informações básicas para que se pudesse considerar o município como integrante da população a ser estudada, cujo detalhamento se apresenta neste tópico.

Devido às limitações da fonte de dados em relação à possibilidade de realização de um filtro específico dos profissionais funcionários de escola, os indicadores elaborados neste estudo foram divididos em três grupos: (1) indicador de vencimento básico médio dos funcionários da educação; (2) indicadores de vencimento básico médio por categoria profissional; e (3) indicadores de vencimento básico médio dos funcionários por local de exercício. Todos estes são indicadores unidimensionais, por realizarem o cálculo estatístico da média apenas na dimensão do vencimento básico. Os três indicadores diferenciam-se entre si pelos filtros aplicados na base de dados, a fim de permitir uma compreensão mais detalhada das condições de remuneração dos profissionais que atuam como funcionários na Região Metropolitana de Curitiba/PR.

Em um primeiro momento, filtrou-se os municípios da Região Metropolitana de Curitiba $(\mathrm{RMC})^{3}$ que declararam a remuneração de "Outros profissionais da educação" durante todo o ano de 2017, conforme Quadro 2, abaixo. Com isso, mantiveram-se 20 municípios, ou seja, $69 \%$ da RMC.

3 De acordo com Lei Complementar Estadual n 139, de 9 de dezembro de 2011, a Região Metropolitana é composta por 29 municípios, listados na Tabela 2. 


\section{Quadro 2 - Detalhamento da constituição da população}

\begin{tabular}{|c|c|c|c|c|c|}
\hline \multirow[b]{2}{*}{$\begin{array}{c}\text { Municípios da Região } \\
\text { Metropolitana de Curitiba } \\
\text { (RMC) }\end{array}$} & \multicolumn{5}{|c|}{ Declarou remuneração } \\
\hline & Em 2017 & $\begin{array}{l}\text { Declarou em } \\
\text { todos os } \\
\text { meses }\end{array}$ & $\begin{array}{l}\text { Declarou "Outros } \\
\text { profissionais da } \\
\text { educação" }\end{array}$ & $\begin{array}{l}\text { Declarou em todos os } \\
\text { meses "Outros } \\
\text { profissionais da } \\
\text { educação" }\end{array}$ & $\begin{array}{l}\text { Incluído na } \\
\text { população }\end{array}$ \\
\hline Adrianópolis & $x$ & $x$ & & & Não \\
\hline Agudos do Sul & $x$ & $x$ & $x$ & $x$ & Sim \\
\hline Almirante Tamandaré & $x$ & $x$ & $x$ & $x$ & Sim \\
\hline Araucária & $x$ & $x$ & $x$ & $x$ & Sim \\
\hline Balsa Nova & $x$ & $x$ & $x$ & $x$ & Sim \\
\hline Bocaiúva do Sul & $x$ & $x$ & $x$ & & Não \\
\hline Campina Grande do Sul & $x$ & $x$ & $x$ & $x$ & Sim \\
\hline Campo do Tenente & $x$ & $x$ & $x$ & $x$ & Sim \\
\hline Campo Largo & $x$ & $x$ & $x$ & $\mathrm{x}$ & Sim \\
\hline Campo Magro & $x$ & $x$ & $x$ & $x$ & Sim \\
\hline Cerro Azul & $x$ & $x$ & $x$ & $x$ & Sim \\
\hline Colombo & $x$ & $x$ & $x$ & $\mathrm{x}$ & Sim \\
\hline Contenda & $x$ & $x$ & $x$ & $x$ & Sim \\
\hline Curitiba & $x$ & $x$ & $\mathrm{x}$ & & Não \\
\hline Doutor Ulysses & $x$ & $x$ & $x$ & $x$ & Sim \\
\hline Fazenda Rio Grande & $x$ & $\mathrm{x}$ & $x$ & $\mathrm{x}$ & Sim \\
\hline Itaperuçu & $x$ & $x$ & $x$ & $x$ & Sim \\
\hline Lapa & $x$ & $x$ & $x$ & & Não \\
\hline Mandirituba & $x$ & $x$ & $x$ & $\mathrm{x}$ & Sim \\
\hline Piên & $x$ & $x$ & & & Não \\
\hline Pinhais & $x$ & $x$ & & & Não \\
\hline Piraquara & $x$ & $\mathrm{x}$ & $\mathrm{x}$ & $\mathrm{x}$ & Sim \\
\hline Quatro Barras & $x$ & $x$ & $x$ & $x$ & Sim \\
\hline Quitandinha & $x$ & $x$ & $x$ & & Não \\
\hline Rio Branco do Sul & $x$ & $x$ & $x$ & $x$ & Sim \\
\hline Rio Negro & $x$ & $\mathrm{x}$ & $x$ & $x$ & Sim \\
\hline São José dos Pinhais & & & & & Não \\
\hline Tijucas do Sul & $x$ & $x$ & & & Não \\
\hline Tunas do Paraná & $x$ & $x$ & $x$ & $x$ & Sim \\
\hline
\end{tabular}

\begin{tabular}{|c|c|}
\hline Total de municípios na RMC & 29 \\
\hline Qtde incluídos na população & 20 \\
\hline \% incluídos na população & $69,0 \%$ \\
\hline
\end{tabular}

Fonte: Elaborado pela autora a partir do SIOPE (FNDE, 2017b). 
Valorização dos funcionários de escola

Ainda, três variáveis tiveram outros dados analisados para constituição da população: 'tipo de categoria', 'carga horária' e 'mês de referência do pagamento'. Os filtros realizados serão detalhados a seguir, e determinaram a composição da base utilizada para elaboração dos indicadores apresentados na seção de resultados. O 'tipo de categoria' filtrado foi 'Outros profissionais da educação', a fim de manter somente os dados referentes aos funcionários da educação, excluindo-se os profissionais do magistério.

$\mathrm{Na}$ análise inicial das categorias referentes ao preenchimento da variável 'carga horária' foram encontradas as seguintes categorias de carga horária: 4, 20, 24, 30, 36, 40, 44, 80, 100, $120,150,160,180,200,220$. Considerando que o município deve imputar o dado de carga horária semanal (FNDE, 2017a), identificou-se possíveis erros no preenchimento do formulário, já que não é possível uma carga horária de, por exemplo, 120 horas semanais. Assim, os municípios que apresentaram pelo menos um caso de profissional com carga horária semanal a partir de 80 horas foram desconsiderados para os indicadores, pois entende-se que é necessário um estudo detalhado do caso, com comparativo de outros documentos municipais, para garantir se as varáveis estão ou não preenchidas corretamente e para compreensão do valor imputado.

Uma vez que a remuneração dos trabalhadores varia mensalmente em decorrência de férias, $13^{\circ}$ salários e outros, foi necessário selecionar um mês particular para análise. Neste artigo, optou-se pelo mês de maio, mesmo mês utilizado para declaração das informações do Censo Escolar pelas escolas brasileiras, uma vez que o próprio sistema apresenta a função de inclusão de informações a partir do censo durante preenchimento pelos municípios (FNDE, 2017a). Essa seleção também tem o intuito de possibilitar pesquisas futuras que façam comparações ou outros tipos de relações entre as duas bases. Assim, realizou-se o filtro para a variável 'mês de referência do pagamento' com a categoria ' 5 '.

Concluindo-se os filtros, restaram para composição da base de análise e apresentação dos resultados a seguir os municípios de Araucária, Balsa Nova, Campina Grande do Sul, Campo do Tenente, Campo Largo, Colombo, Contenda, Itaperuçu, Piraquara e Rio Negro.

\section{O vencimento básico médio dos profissionais da educação}

Para os resultados apresentados nesta seção, utilizou-se a base de dados com os dez municípios mencionados na seção anterior, ou seja, que apresentaram registro da remuneração com recursos do Fundeb dos profissionais da educação que não atuam no magistério, a partir das informações declaradas pelos municípios no SIOPE, para o mês de maio de 2017. No total, contabilizaram-se 1.486 registros de pagamento na base, categorizados em três tipos de funções e em 213 instituições, sendo cinco Secretarias Municipais de Educação. Devido à variação das cargas horárias semanais de trabalho entre 20 e 44 horas nos registros, foi realizada a padronização em 40 horas semanais (ALVES; SONOBE, 2018), uma vez que essa carga horária corresponde a $88,6 \%$ dos casos apresentados.

$\mathrm{Na}$ Tabela 2, abaixo, constam as medidas descritivas encontradas, em que constam as características escolhidas para apresentação dos dados. Elas estão expostas de acordo com os três grupos de indicadores mencionados anteriormente: (1) indicador de vencimento básico médio dos funcionários da educação, diferenciando profissionais do magistério (ainda que em função de gestão) dos outros profissionais da educação; (2) indicadores de vencimento básico 
médio por categoria profissional, das encontradas entre os registros de funcionários; e (3) indicadores de vencimento básico médio dos funcionários por local de exercício.

Tabela 2 - Medidas descritivas do vencimento básico (carga horária padronizada 40h) pago com recursos oriundos do Fundeb para "outros profissionais da educação"*, instituições municipais, RMC ${ }^{* *}$, Maio/2017

\begin{tabular}{|c|c|c|c|c|c|c|}
\hline $\begin{array}{l}\text { Medidas } \\
\text { Descritivas }\end{array}$ & $\begin{array}{l}\text { (1) Outros } \\
\text { profissionais da } \\
\text { educação }\end{array}$ & $\begin{array}{c}\text { Auxiliar/ } \\
\text { Assistente } \\
\text { Educacional }\end{array}$ & $\begin{array}{l}\text { crição da Categor } \\
\text { Profissionais que } \\
\text { atuam na } \\
\text { realização das } \\
\text { atividades } \\
\text { requeridos nos } \\
\text { ambientes de } \\
\text { secretaria, de } \\
\text { manutenção em } \\
\text { geral. }\end{array}$ & $\begin{array}{l}\text { Profissional } \\
\text { Profissionais que } \\
\text { exercem funções de } \\
\text { secretaria escolar, } \\
\text { alimentação escolar } \\
\text { (merendeiras), } \\
\text { multimeios didáticos } \\
\text { e infraestrutura. }\end{array}$ & $\begin{array}{c}\text { Secretaria } \\
\text { Municipal ou } \\
\text { Departamento } \\
\text { de Educação }\end{array}$ & Escolas e outros \\
\hline $\begin{array}{l}\text { Número de } \\
\text { profissionais }\end{array}$ & 1.486 & 398 & 218 & 870 & 94 & 1.392 \\
\hline $\begin{array}{l}\text { Total de } \\
\text { Vencimento }\end{array}$ & $\mathrm{R} \$ 2.251 .884,66$ & $\mathrm{R} \$ 746.212,50$ & $\mathrm{R} \$ 393.313,81$ & $\mathrm{R} \$ 1.112 .358,35$ & $\mathrm{R} \$ 169.763,80$ & $\mathrm{R} \$ 2.082 .120,86$ \\
\hline Média & $R \$ 1.515,40$ & $\mathrm{R} \$ 1.874,91$ & $\mathrm{R} \$ 1.804,19$ & $\mathrm{R} \$ 1.278,57$ & $\mathrm{R} \$ 1.806,00$ & $R \$ 1.495,78$ \\
\hline $\begin{array}{l}\text { Desvio- } \\
\text { padrão }\end{array}$ & $\mathrm{R} \$ 794,74$ & $\mathrm{R} \$ 843,48$ & $\mathrm{R} \$ 1.212,70$ & $\mathrm{R} \$ 500,81$ & $\mathrm{R} \$ 1.269,13$ & $\mathrm{R} \$ 748,68$ \\
\hline Amplitude & $\mathrm{R} \$ 8.773,11$ & $\mathrm{R} \$ 4.022,77$ & $\mathrm{R} \$ 8.687,24$ & $\mathrm{R} \$ 4.725,35$ & $\mathrm{R} \$ 8.396,11$ & $\mathrm{R} \$ 5.363,94$ \\
\hline Mínimo & $\mathrm{R} \$ 560,00$ & $\mathrm{R} \$ 977,23$ & $\mathrm{R} \$ 645,87$ & $\mathrm{R} \$ 560,00$ & $\mathrm{R} \$ 937,00$ & $\mathrm{R} \$ 560,00$ \\
\hline $\begin{array}{r}10 \% \\
\text { menores }\end{array}$ & $\mathrm{R} \$ 977,23$ & $\mathrm{R} \$ 1.014,00$ & $\mathrm{R} \$ 937,00$ & $\mathrm{R} \$ 937,00$ & $\mathrm{R} \$ 1.007,28$ & $\mathrm{R} \$ 977,23$ \\
\hline $1^{\circ}$ quartil & $\mathrm{R} \$ 1.016,32$ & $\mathrm{R} \$ 1.171,61$ & $\mathrm{R} \$ 1.057,13$ & $\mathrm{R} \$ 981,41$ & $\mathrm{R} \$ 1.114,98$ & $\mathrm{R} \$ 1.014,00$ \\
\hline Mediana & $\mathrm{R} \$ 1.207,03$ & $\mathrm{R} \$ 1.382,23$ & $\mathrm{R} \$ 1.374,27$ & $\mathrm{R} \$ 1.129,16$ & $\mathrm{R} \$ 1.274,19$ & $\mathrm{R} \$ 1.207,03$ \\
\hline $3^{\circ}$ quartil & $\mathrm{R} \$ 1.610,09$ & $\mathrm{R} \$ 2.569,47$ & $\mathrm{R} \$ 1.905,29$ & $\mathrm{R} \$ 1.362,05$ & $\mathrm{R} \$ 2.018,33$ & $\mathrm{R} \$ 1.553,98$ \\
\hline $10 \%$ maiores & $\mathrm{R} \$ 2.569,47$ & $\mathrm{R} \$ 2.826,41$ & $\mathrm{R} \$ 3.608,75$ & $\mathrm{R} \$ 1.735,83$ & $\mathrm{R} \$ 2.816,45$ & $\mathrm{R} \$ 2.569,47$ \\
\hline Máximo & $\mathrm{R} \$ 9.333,11$ & $\mathrm{R} \$ 5.000,00$ & $\mathrm{R} \$ 9.333,11$ & $\mathrm{R} \$ 5.285,35$ & $\mathrm{R} \$ 9.333,11$ & $\mathrm{R} \$ 5.923,94$ \\
\hline
\end{tabular}

*Profissionais não categorizados como "Profissionais do magistério".

${ }^{* *}$ Foram considerados, conforme metodologia apresentada, os municípios de: Araucária, Balsa Nova, Campina Grande do Sul, Campo do Tenente, Campo Largo, Colombo, Contenda, Itaperuçu, Piraquara e Rio Negro.

Fonte: Elaborado pela autora a partir do SIOPE (FNDE, 2017b).

As medidas apresentam como resultado para o indicador (1) uma média de vencimento básico de $\mathrm{R} \$ 1.515,40$ para os trabalhadores de tipo de categoria "Outros profissionais da educação", neste artigo compreendidos como funcionários da educação. Dentre as três possibilidades de descrição da categoria incluídas no grupo de indicadores (2), percebe-se "Auxiliar/Assistente Educacional" com maior vencimento básico médio, de $\mathrm{R} \$ 1.874,91$; em seguida "Profissionais que atuam na realização das atividades requeridos nos ambientes de secretaria, de manutenção em geral", com vencimento básico médio de $\mathrm{R} \$ 1.804$,19; e, por último, a categoria "Profissionais que exercem funções de secretaria escolar, alimentação escolar (merendeiras), multimeios didáticos e infraestrutura”, com vencimento básico médio de $\mathrm{R} \$ 1.278,57$. Ainda que o nome desta última categoria remeta à nomenclatura das funções dos funcionários da escola, explícita no Parecer CNE/CEB 16/2005, 69 dos 94 casos que possuem como local de exercício a Secretaria Municipal ou Departamento de Educação 
Valorização dos funcionários de escola

registram essa descrição. Portanto, entendeu-se que não é possível limitar a análise do vencimento específico de funcionários de escola no filtro a partir dessa descrição.

Dos locais de exercício apresentados, foi possível filtrar as Secretarias Municipais ou Departamentos de Educação das escolas e outras instituições (associações e outros), conforme grupo de indicadores (3). Quando observado por esse filtro, verifica-se que o vencimento básico médio dos funcionários da educação, incluindo-se as três categorias, atuantes nas Secretarias e Departamentos é maior do que das escolas e outros, sendo R\$ $1.806,00$ e $\mathrm{R} \$ 1.495,78$, respectivamente.

Observa-se que o menor salário, de $\mathrm{R} \$ 560,00$, está abaixo do salário mínimo para o ano de 2017 , de $R \$ 937,00$. No entanto, uma verificação da remuneração final apresentada nesse caso específico no registro do SIOPE, indica um valor final de remuneração de $R \$ R \$$ 1.145,23. Contudo, considerando somente as informações contidas nessa base não foi possível compreender com mais detalhes esse tipo de situação. O maior salário, de $\mathrm{R} \$$ 9.333,11, foi pago para um profissional atuante em Secretarias e Departamentos. Em todas os indicadores observa-se uma grande amplitude, ou seja, uma grande diferença entre o menor e o maior vencimento. Essa amplitude é sempre maior do que duas vezes a média do vencimento em todos os grupos apresentados.

Ainda que a média geral seja de $\mathrm{R} \$ 1.515,40$, a mediana nos indica que $50 \%$ dos funcionários recebeu até $\mathrm{R} \$ 1.207,03$, ou seja, $79,7 \%$ da média. Uma análise do $3^{\circ}$ quartil, que apresenta o valor inicial do vencimento dos $25 \%$ de funcionários que têm os maiores vencimentos, nos mostra que, mesmo com o maior salário acima de nove mil reais, $75 \%$ dos profissionais receberam até $\mathrm{R} \$ 1.610,09$, ou seja, $6,2 \%$ acima da média. Os dados apontaram ainda que $10 \%$ dos funcionários recebeu até $R \$ 977,23$, e que nos $10 \%$ de funcionários que receberam os maiores vencimentos, estão os valores entre $R \$ 2.569,47$ e $R \$ 9.333,11$. Na comparação do desvio-padrão entre as categorias (2), que apresenta o grau de variação entre os vencimentos considerados para a composição do indicador, destaca-se uma maior dispersão entre os profissionais dos ambientes de secretaria e uma menor dispersão entre os auxiliares. A mesma análise para os diferentes locais de exercício (3) demonstra que há maior variação dentre os que trabalham em secretarias em comparação com os que trabalham em escolas.

Em uma relação com o salário mínimo de 2017 ( $R \$ 937,00)$, observa-se que $75 \%$ dos profissionais categorizados como "Outros profissionais da educação" (1) receberam até 1,7 salários mínimos para uma jornada de 40 horas semanais, sendo que, para os profissionais com local de exercício (3) em secretarias municipais e departamentos de educação, esse valor sobe para até 2,2 salários mínimos.

\section{Considerações Finais}

Este artigo buscou contribuir com o debate em torno da valorização dos profissionais da educação, mais precisamente dos funcionários de escola, tendo por referência a Região Metropolitana da cidade de Curitiba, no Paraná. A comparação entre a legislação referente a planos de carreira e remuneração desses profissionais com as dos profissionais do magistério mostrou que existem diferenças de conquistas como, por exemplo, o PSPN instituído apenas para docentes. Ainda, o levantamento do perfil e condições de remuneração que podem permitir desenvolvimento e monitoramento de políticas educacionais vem sendo feito com 
Valorização dos funcionários de escola

prioridade para os profissionais do magistério, como no caso do censo escolar que detalha apenas o perfil dos profissionais docentes. Nesse sentido, propôs-se aqui indicadores para análise do vencimento básico dos funcionários de escola, a partir dos dados de remuneração oriundos do Fundeb declarados pelos municípios no SIOPE.

Devido à recente implementação do formulário que gera a base de dados, buscou-se em um primeiro momento realizar uma exploração inicial nos registros, nos quais foram encontradas diversas limitações para seu uso na pesquisa. A redução do escopo inicial de 29 municípios da Região Metropolitana de Curitiba para 10 municípios representa essa situação. Destaca-se que apenas $46,8 \%$ dos municípios paranaenses incluíram registro de "Outros profissionais da educação" durante todos os meses do ano de 2017. Ainda, foram observados erros nos preenchimentos dos dados (como carga horária semanal igual ou superior a $80 \mathrm{~h}$ ) e inconsistências na declaração de remuneração que não são passíveis de verificação sem comparação com outras fontes. Uma hipótese para a não declaração é a contratação de temporários, que não teriam seus pagamentos realizados com recursos do Fundeb.

A partir dos dados dos municípios cujos registros demonstravam consistência nos filtros de declaração de funcionários, imputação de registros em todos os meses do ano e carga horária semanal, formou-se uma base de análise com os municípios Araucária, Balsa Nova, Campina Grande do Sul, Campo do Tenente, Campo Largo, Colombo, Contenda, Itaperuçu, Piraquara e Rio Negro. No entanto, não foi possível analisar apenas os funcionários de escola, sendo o resultado apresentado para funcionários da educação no geral, excluindo-se os profissionais do magistério.

Neste estudo demonstrou-se que, considerando os limitadores da base de dados, os funcionários da educação, atuantes em nível municipal nas cidades mencionadas anteriormente, constituintes da RMC, receberam, em maio de 2017 , uma média de $R \$$ 1.515,48 para a carga horária de 40 horas semanais, totalizando 1,6 salários mínimos, sendo que $75 \%$ desses profissionais receberam até $R \$ 1.610,09$, totalizando 1,7 salários mínimos. Também foi possível verificar que, entre os $10 \%$ de funcionários que ganharam os maiores vencimentos, encontram-se aqueles com registros entre $\mathrm{R} \$ 2.569,47$ e $\mathrm{R} \$ 9.333,11$. Ou seja, apenas $10 \%$ dos funcionários receberam entre 2,7 e 10 salários mínimos. $E$ que, separandose os profissionais por local de exercício, os funcionários registrados com atuação em secretarias municipais de educação e departamentos de educação tiveram vencimento, em média, $17,2 \%$ maior do que os registrados em escolas e outros locais. Ainda, no geral, a diferença entre o maior vencimento dos $10 \%$ que recebiam menos e o maior vencimento dos $10 \%$ que recebiam mais foi de 9,5 vezes.

Entende-se que há necessidade de mais estudos sobre a fonte de dados, inclusive estudos que foquem na remuneração dos profissionais do magistério, também disponível no SIOPE, e que compreendam com maior detalhamento o processo realizado em nível municipal para envio de informações ao formulário, permitindo também a verificação mais detalhada dos registros declarados.

Por fim, o estudo permite observar que, no caso do preenchimento correto das informações e da disponibilização de dados que permitam a comparação dessa base com outros dados disponibilizados pelo Ministério da Educação, INEP e outros, este relatório pode se constituir em uma importante ferramenta para acompanhamento das condições de 
Valorização dos funcionários de escola

remuneração dos funcionários e funcionárias de escola, dos profissionais do magistério e do próprio Fundeb.

\section{Referências}

ALVES, T.; SONOBE, A. K. Remuneração Média como indicador da valorização docente no mercado de trabalho. Cadernos de Pesquisa, São Paulo, v. 48, n. 168, p. 446-476, abr.-jun. 2018.

ASSIS, L. M. Desenvolvimento, aprimoramento e consolidação de educação de qualidade. Goiânia: CNE/UNESCO, 2015. Documento técnico. Disponível em: <http://portal.mec.gov.br/index.php?option=com_docman\&view=download\&alias=26091diagnostico-iniciativas-formacao-inicial-continuada-profissionais-edfisica-basicapdf\&Itemid=30192> . Acesso em: 01 ago. 2018.

ASSIS, L. M. Funcionários administrativos - Um balanço crítico da EB. Revista Retratos da Escola, Brasília, v. 11, n. 21, p. 641-661, jul./dez. 2017.

BRASIL. Emenda Constitucional no 14, de 12 de setembro de 1996. Modifica os arts. 34, 208, 211 e 212 da Constituição Federal e dá nova redação ao art. 60 do Ato das Disposições constitucionais Transitórias. Diário Oficial da União, Brasília, 1996a. Disponível em: $<$ http://www.planalto.gov.br/ccivil_03/Constituicao/Emendas/Emc/emc14.htm>. Acesso em: 01 ago. 2018.

BRASIL. Lei $n^{\circ}$ 9.394, de 20 de dezembro de 1996. Estabelece as diretrizes e bases da educação nacional. Diário Oficial da União, Brasília, 1996b. Disponível em: <http://www.p analto.gov.br/CCIVIL_03/leis/L9394.htm>. Acesso em: 01 ago. 2018.

BRASIL. Conselho Nacional de Educação. Câmara de Educação Básica. Resolução CNE/CEB $n^{\circ}$ 5, de 22 de novembro de 2005. Inclui, nos quadros anexos à Resolução CNE/CEB no 4/99, de 22/12/1999, como 21ª Área Profissional, a área de Serviços de Apoio Escolar. Brasília, 2005a. Disponível em: <http://portal.mec.gov.br/setec/arquivos/pdf/ legisla_resol05.pdf>. Acesso em: 01 ago. 2018.

BRASIL. Conselho Nacional de Educação. Câmara de Educação Básica. Parecer CNE/CEB $n^{\circ}$ 16, de 3 de agosto de 2005. Proposta de Diretrizes Curriculares Nacionais para a área profissional de Serviços de Apoio Escolar. Brasília, 2005b. Disponível em: <http://portal.mec.gov.br/cne/arquivos/pdf/pceb016_05.pdf>. Acesso em: 01 ago. 2018.

BRASIL. Emenda Constitucional $n^{\circ} 53$, de 19 de dezembro de 2006. Dá nova redação aos arts. $7^{\circ}, 23,30,206,208,211$ e 212 da Constituição Federal e ao art. 60 do Ato das Disposições Constitucionais Transitórias. Diário Oficial da União, Brasília, 2006. Disponível em: <http://www.planalto.gov.br/ccivil_03/constituicao/emendas/emc/emc53.htm>. Acesso em: 01 ago. 2018.

BRASIL. Lei $n^{\circ} 11.494$, de 20 de junho de 2007. Regulamenta o Fundo de Manutenção e Desenvolvimento da Educação Básica e de Valorização dos Profissionais da Educação FUNDEB, de que trata o art. 60 do Ato das Disposições Constitucionais Transitórias; altera a Lei no 10.195, de 14 de fevereiro de 2001; revoga dispositivos das Leis nos 9.424, de 24 de dezembro de 1996, 10.880, de 9 de junho de 2004, e 10.845, de 5 de março de 2004; e dá 
Valorização dos funcionários de escola

outras providências. Diário Oficial da União, Brasília, 2007. Disponível em: <http://www.planalto.gov.br/ccivil_03/_ato2007-2010/2007/lei//11494.htm>. Acesso em: 01 ago. 2018.

BRASIL. Lei n 11.738, de 16 de julho de 2008. Regulamenta a alínea "e" do inciso III do caput do art. 60 do Ato das Disposições Constitucionais Transitórias, para instituir o piso salarial profissional nacional para os profissionais do magistério público da educação básica. Diário Oficial da União, Brasília, 2008a. Disponível em: <http://www.planalto.gov.br/ccivil_03/_a to2007-2010/2008/lei/111738.htm>. Acesso em: 01 ago. 2018.

BRASIL. Conselho Nacional de Educação. Câmara de Educação Básica. Resolução CNE/CEB $n^{\circ}$ 1, de 27 de março de 2008. Define os profissionais do magistério, para efeito da aplicação do art. 22 da Lei no 11.494/2007, que regulamenta o Fundo de Manutenção e Desenvolvimento da Educação Básica e de Valorização dos Profissionais da Educação FUNDEB. Brasília, 2008b. Disponível em: <http://portal.mec.gov.br/setec/arquiv os/pdf/rceb001_08.pdf>. Acesso em: 01 ago. 2018.

BRASIL. Lei $n^{\circ} 12.014$, de 6 de agosto de 2009. Altera o art. 61 da Lei no 9.394, de 20 de dezembro de 1996, com a finalidade de discriminar as categorias de trabalhadores que se devem considerar profissionais da educação. Diário Oficial da União, Brasília, 2009a. Disponível em: <http://www.planalto.gov.br/ccivil_03/_ato2007-2010/2009/lei//12014.htm>. Acesso em: 01 ago. 2018.

BRASIL. Conselho Nacional de Educação. Câmara de Educação Básica. Resolução CNE/CEB $n^{\circ}$ 2, de 28 de maio de 2009. Fixa as Diretrizes Nacionais para os Planos de Carreira e Remuneração dos Profissionais do Magistério da Educação Básica Pública. Brasília, 2009b. Disponível em: <http://portal.mec.gov.br/dmdocuments/resolucao_cne_c eb002_2009.pdf>. Acesso em: 01 ago. 2018.

BRASIL. Conselho Nacional de Educação. Câmara de Educação Básica. Resolução CNE/CEB $n^{\circ} \mathbf{5}$, de 3 de agosto de 2010. Fixa as Diretrizes Nacionais para os Planos de Carreira e Remuneração dos Funcionários da Educação Básica Pública. 2010. Disponível em: <http://portal.mec.gov.br/docman/fevereiro-2011-pdf/7601-resolucao5-30610-cne-pdf>.

Acessado em: 01/08/2018.

BRASIL. Lei n 13.005, de 25 de junho de 2014. Aprova o Plano Nacional de Educação - PNE e dá outras providências. Diário Oficial da União, Brasília, 2014. Disponível em: <http://www.planalto.gov.br/ccivil_03/_ato2011-2014/2014/lei//13005.htm>. Acesso em: 01 ago. 2018.

EDNIR, M.; BASSI, M. Bicho de sete cabeças: para entender o financiamento da educação brasileira. São Paulo: Editora Peirópolis, 2009.

FNDE. Fundo Nacional de Desenvolvimento da Educação. Manual de Orientação do SIOPE. 2017a. Disponível em: <http://www.fnde.gov.br/fnde_sistemas/siope/sobre/manuais-dosiope>. Acesso em: 01 ago. 2018.

FNDE. Fundo Nacional de Desenvolvimento da Educação. Consultar Remuneração dos Profissionais da Educação - FUNDEB. 2017b. Disponível em: <https://www.fnde.gov.br/ siope/consultarRemuneracaoMunicipal.do>. Acesso em: 01 ago. 2018. 
Valorização dos funcionários de escola

GOUVEIA, A.; BASSI, M. Vencimento dos professores no contexto das finanças públicas do Paraná e de Santa Catarina, Brasil. Revista Educação em Questão, Natal, v. 54, n. 40, p. 101-128, jan./abr. 2016.

GROCHOSKA, M. A. Políticas educacionais e a valorização do professor: carreira e qualidade de vida dos professores de educação básica do município de São José dos Pinhais/PR. 2015. Tese (Doutorado em Educação) - Universidade Federal do Paraná, Curitiba, 2015.

MONLEVADE, J. Identidade, carreira e jornada dos profissionais da educação. Cadernos de Educação, Brasília, n. 26, p. 79-97, jan./jun. 2014.

PARANÁ. Lei complementar $n^{\circ} 139$, de 9 de dezembro de 2011. Diário Oficial do Paraná, Curitiba, 12 dez. 2011. Disponível em: <http://www.legislacao.pr.gov.br/legislacao/ pesquisarAto.do?action=exibir\&codAto $=62625 \& \operatorname{codTipoAto}=\&$ tipoVisualizacao=alterado $>$. Acesso em: 01 ago. 2018.

TRIOLA, M. F. Introdução à estatística. Rio de Janeiro: LTC Editora, 1998.

Mariana Moschkovich Athayde é mestranda na linha de Políticas Educacionais do Programa de Pós-Graduação em Educação da Universidade Federal do Paraná (UFPR). Licenciada em Pedagogia, Bacharel em Comunicação Social - Habilitação em Jornalismo e Especialista em Tecnologia e Educação a Distância. Tem experiência como Professora Tutora Presencial na UniOpet e Tutora Online no IFPR.

ORCID: http://orcid.org/0000-0001-5514-7956

E-mail: mari_athayde@yahoo.com.br

Recebido em 28 de fevereiro de 2019

Aprovado em 14 de abril de 2019 


\section{Editores do volume 10}

Márcia Aparecida Jacomini - Universidade Federal de São Paulo, Brasil

José Marcelino de Rezende Pinto - Universidade de São Paulo, Brasil

\section{Comitê Editorial}

Nalú Farenzena - Universidade Federal do Rio Grande do Sul, Brasil

Juca Gil - Universidade Federal do Rio Grande do Sul, Brasil

Theresa Adrião - Universidade Estadual de Campinas, Brasil

Ângelo Ricardo de Souza - Universidade Federal do Paraná, Brasil

\section{Conselho Editorial}

\section{Alejandro Morduchowicz}

Universidad Pedagógica, Provincia de Buenos Aires, Argentina

Andréa Barbosa Gouveia

Universidade Federal do Paraná, Brasil

Fernanda Saforcada

Universidade de Buenos Aires, Argentina

Jacques Velloso

Universidade de Brasília, Brasil

João Monlevade

Senado Federal, Brasil

Jorge Abrahão de Castro

Instituto de Pesquisa Econômica Aplicada / IPEA, Brasil

Lisete Regina Gomes Arelaro

Universidade de São Paulo, Brasil

Luis Carlos Sales

Universidade Federal do Piauí, Brasil

Luiz de Sousa Junior

Universidade Federal da Paraíba, Brasil

Luiz Fernandes Dourado

Universidade Federal de Goiás, Brasil

Magna França

Universidade Federal do Rio Grande do Norte, Brasil

Marcos Edgar Bassi

Universidade Federal de Santa Catarina, Brasil

Maria Angélica Pedra Minhoto

Universidade Federal de São Paulo, Brasil

Maria Beatriz Luce

Universidade Federal do Rio Grande do Sul, Brasil

Maria Dilnéia Espíndola Fernandes

Universidade Federal de Mato Grosso do Sul, Brasil

Nelson Cardoso do Amaral

Universidade Federal de Goiás, Brasil

Nicholas Davies

Universidade Federal Fluminense, Brasil

Robert E. Verhine

Universidade Federal da Bahia, Brasil

Romualdo Portela de Oliveira

Universidade de São Paulo, Brasil

Rosana Gemaque Rolim

Universidade Federal do Pará, Brasil

Rubens Barbosa de Camargo

Universidade de São Paulo, Brasil

Theresa Adrião

Universidade Estadual de Campinas, Brasil

Tristan McCowan

University of London, Reino Unido

Vera Jacob

Universidade Federal do Pará, Brasil

Vera Peroni

Universidade Federal do Rio Grande do Sul, Brasil

Vitor Henrique Paro

Universidade de São Paulo, Brasil

\section{Equipe editorial}

Apoio ao Comitê Editorial: Caio Cabral da Silva

Diagramação, Revisão de português e normalização: Edson Leonel de Oliveira

Revisão de inglês: Sabrina Ferreira

Fineduca - Revista de Financiamento da Educação

Associação Nacional de Pesquisa em

Financiamento da Educação

e-mail: revista.fineduca@gmail.com | site: http://seer.ufrgs.br/fineduca 